Embedding new science into practice - lessons from the development and application of a Performance-based asset management system

\author{
C. Mitchell, 0. Tarrant, D. Denness, P. Sayers, J. Simm \\ \& M. Bramley
}

Reproduced from:

Flood Risk Management - Research and Practice Proceedings of FLOODrisk 2008

Keble College, Oxford, UK

30 September to 2 October 2008 


\title{
Embedding new science into practice - lessons from the development and application of a Performance-based asset management system
}

\author{
C. Mitchell, O. Tarrant \& D. Denness \\ Environment Agency, UK \\ P. Sayers \& J. Simm \\ HR Wallingford, Wallingford, Oxfordshire, UK \\ M. Bramley \\ Independent Advisor to Defra/Environment Agency F\&CERM R\&D Programme, UK
}

\begin{abstract}
The UK Environment Agency is developing an improved performance and risk based approach to asset management associated with flood and coastal defences. This utilises a number of advances made within the research community over the past five-ten years, in particular the so-called PAMS methods-Performancebased Asset Management System. Delivering innovation into practice however requires significant effort, and this effort is often under-estimated.

This paper explores the barriers and facilitators of moving innovative and potentially beneficial science into good practice. This is done with reference to specific examples drawn from the development of the PAMS including issues associated with achieving buy-in from multiple users. For example take-up can be undermined by researchers through over-selling the utility and readiness of the science as well as by potential users through resistance to change and perceived loss of commercial advantage. An important means of overcoming these hurdles is the process of piloting and independent verification of the methods. This paper explores how close working with specific end-users within the Thames Estuary Flood Risk Management Planning Team (TE2100) team as well as national and local Environment Agency (EA) asset management staff has helped build trust in the science and demonstrate its benefits.

Access to the new tools, user skill and training, and crucially the on-going support for these, also plays an important part. Through the UK Conveyance Estimation System (CES) the research community has significantly improved the way that managers can explore the impact of changes to management practice on channel performance. Delivering the CES tool into practice however has highlighted the time and effort needed to implement a new software product as an operational tool-for example, dealing with liability, Intellectual Property Rights (IPR), Information Technology (IT); support and training as well as developing and embedding associated policy guidance. Where new tools challenge existing paradigms and traditional approaches take up can be slow. There is an onus on researchers to engage with, and demonstrate utility to, industry and there is an onus on industry to be willing to accommodate change. For example PAMS includes a move towards reliability-based assessment of asset performance under load. Concepts of fragility curves, where performance is considered probabilistically across a wide spectrum of loading, challenge a more traditional deterministic consideration of design loads. This paper highlights how close working with engineering practice through examples and sequential steps forward has helped explore these issues and promote take-up; it also highlights
\end{abstract} how difficult this road can sometimes be.

\section{INTRODUCTION}

As more is demanded of decision makers so our underlying science necessarily becomes more advanced and the tools more complex. Delivering these developments into practice in timely manner is fraught with difficulties - users often perceive new 'science' as unproven and non-usable. This may result from poor science and development but often it reflects a tendancy for users to change their requirements or expect more of the science than is contracted to be delivered. Both researchers and users tend to 
underestimate the time required to develop innovative tools and techniques solutions - often to meet the demands of a changing policy . An increased awareness of the challenges being faced from both the enduser and the scientists perspective could lead to a far more successful uptake of science into practice and a more progressive evolution of tools and techniques.

\section{THE PROCESS - SCIENCE INTO PRACTICE}

Under the guidance of a five year research strategy (Defra/EA, 2008), the Sustainable Asset Management (SAM) Theme Advisory Group (TAG) considers and robustly prioritises approximately 40 proposals each year. The prioritisation is based on: the benefits of carrying out the research; the likelihood of successfully completing the research; whether the proposal underpins the priority demands of users and an understanding of how the scientific advances can be applied in practice. Notably, the cost of the research is not considered at this early prioritisation stage.

Experience in the SAM TAG shows that this process is effective in identifying key research priorities. These are grouped within four categories;

1. identifying and attributing risk associated with the management of flood defence assets

2. recognising the state, condition and performance of the assets

3. understanding and monitoring the performance of asset systems, where a system is defined as 'a collection of assets which are dependent upon each other for flood defence'

4. delivery of improved best practice guidance

Once the cost is placed into the prioritisation process, the well considered benefits make it easier to identify which "science" delivers best value for money. The process of considering cost as a secondary component drives the 'customer orientated' priority listings forward and can help drive innovation within the funding mechanisms (e.g. collaboration).

The Science which underpins these four areas can be split into three further sub headings - tools, techniques and guidance. Tools tackle specific asset management tasks e.g. software, a system or a simple 'look-up' table. Techniques outline the methodological principles in order to manage assets e.g. how to survey an asset. Guidance is essential for underpinning the asset management industry, and often results in a manual, guide or handbook and/or training (refer to section 4). Often all three are needed to be in place before take-up.

The SAM theme also recognises the importance of science which feeds straight back into advancing scientific knowledge. This category is also where 'blue-sky' research would be carried out, reviewing and scoping a way forward. These last two types of research are an important component of any science programme and are often very difficult to justify against other proposals with more short-term scientific outputs. By clearly stating the potential use of the science in the distant future, the proposal can more easily be assessed.

\section{THE DEVELOPMENT AND APPLICATION OF SCIENCE}

They key to good scientific development and successful application lies in the project management system. A good project management system will use a whole lifecycle approach and have identified the risks involved in the projects structure, providing a framework to address these. Within a project lifecycle (Figure 1) Stage 1 can be recognised as an ideas stage, where a pre-feasibility analysis is carried out to help refine the ideas into a concept worth taking forward. For the PAMS project the question posed was 'How identify and prioritise improvement and maintenance works?' This broad question lies at the heart of PAM and even at this early stage it was essential to have strong engagement with the potential end users in order to understand and agree in more specific terms what was required. However it was equally important not to specify the how at this stage - as Henery Ford famously remarked "if I had asked what people wanted they would have said faster horses".

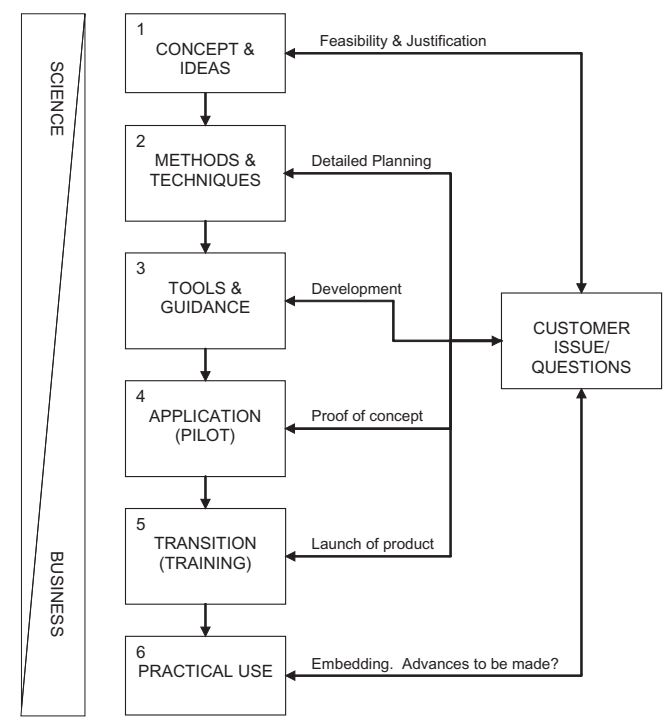

Figure 1. A research project lifecycle, identifying the key stages of a research project and outlining the key communication channels. 
Therefore it is important to understand the decision to be made but it is not always appropriate for the user to specify the exact nature of the support.

The time to undertake stage 2 is often underestimated. This is where much of the technical developments were planned to underpin the PAMS. For example, how to develop the technical requirements for reliability analysis, failure modes and fragility relationships. The end-user input at this stage was vital, so that the planned programme and the key outputs (e.g. guidance, reports) could be agreed within a timescale. Stage 3, the developmental stage, is often delivered in phases or sub stages. The PAMS project was reviewed at each of the sub stages ensuring that developments in the project were reconsidered against the original plan. This review often led to further suggestions of development, which were assessed and either put on hold, taken up within the PAMS project through a change process e.g. the condition assessment manual, or initiated as a separate project that could feed back into the PAMS project e.g. Asset deterioration and whole life costing assessment project (EA: SC060078).

Stage 4 is discussed in some detail in section 6, where the research is piloted at several field sites to prove the concepts. Important flexibility was provided within the PAMS project for the team to react and assess their findings against the Summer 2007 floods. This proved very successful when reviewing asset condition grades, where the review suggested that the condition grades for each structure type at a loading equivalent to its declared Standard of Protection was probably conservative and as such the guidance on setting target condition grades could be improved. The cost savings of this finding were instantly recognisable.

Stage 5 is a vital stage for ensuring science is used in practice. A project developing a Conveyance Estimation System (CES) included a number of training sessions on the product; funded by the end-users under the research project and run jointly between the science and operational teams (McGahey et al. 2008). This enabled a wider number of key end users to fully appreciate the potential of the tool, ultimately applying pressure to incorporate the tool into current practice. Changing business processes can be extremely difficult, and although not the responsibility of the science project, it is made easier if the science can help identify potential use. Often the training required to alter the business mindset itself is forgotten at the initiation of a project.

The main component within stage 6 for the PAMS project is currently evolving, reacting to the development of the Asset Management IT system (AMIT). It is under this system that PAMS will provide some of the key analysis tools. AMIT was initiated in the final year of the 4 year PAMS project (phase 2) and as such the PAMS system architecture has had to be reconsidered. Notably, the method of delivery, (e.g. CIS) will have requirements which are independent to the Science.

Overall the project lifecycle is necessarily time intensive and complex in order to minimise risk. However, it has the ability to cope with constantly evolving business/user needs and the common demand for developments in a very short time frame. The PAMS project managed changing demands by constantly refining and adapting the project, listening very carefully to the changes being made at the users end. Although uncommon, there are examples available of research which initiated under high demand, but disconnect to changes in the user environment (in work, legislative drivers and people) during the duration of the project tended to result in the frustrating comment 'why are you carrying out that science, its not what we see as a priority'.

\subsection{Making changes to the project plan}

Scientific projects tend to have the highest number of requests to adapt the original project plan. This tends to be because the later stages of the project can not be planned in any detail until the initial stages are complete. By breaking the project into stages or phases it makes it easier to identify when key outcomes arise. At these breakpoints or milestones, careful reassessment is suggested to ensure the project is still on route to delivering its objectives. Where a break occurs however, continuity in staffing and momentum can be compromised causing unnecessary complications and delays (unless specifically desired).

The PAMS project experienced two key revisions to the original project plan which resulted in a number of 'measured steps forward' (MSF) being developed. The first revision (MSFs 1-6) was due to the recognition with the users that many of the individual scientific advances could be delivered into practical use before the project as a whole had delivered. For example, analysis of channel management led to EA guidance notes being released, and the review of asset fragility and failure led to an update in the Condition Assessment Manual (CAM) which enables asset owners to consider performance issues better in allocating a condition grade to their assets. The second (MSFs 7-14) was due to the implementation of the EA Asset Management Strategy which warranted a refocus to address the support of newly developed SAMP's-System Asset Management Plans and the development of AMIT-The Asset Management IT system.

As a result of the Summer 2007 floods two further studies were initiated, one for the immediate provision of updated data on deterioration rates and 
maintenance costs, and the second for guidance on setting more realistic target condition grades for assets. It was important to be aware of these parallel projects, so that smart use of what had been learnt from the floods could be applied within the PAMS project.

\section{AN APPROACH FOR GOOD PRACTICE GUIDES}

The Defra/EA Flood and Coastal Erosion Risk Management (F\&CERM) science programme is seeking to produce (through updating where appropriate) a comprehensive set of guidance on the management of the principal F\&CERM asset types. It is essential that the guides be in an appropriate format and written in plain English from the viewpoint of the end user. In this case the end user is often the Operating Authority Asset Manager, who has the task of owning, maintaining, upgrading, adding to and disposing of its stock of flood or coastal defence or drainage infrastructure. With this in mind the structure of the guide should reflect the range of the asset managers tasks, from monitoring and responding to emergencies, to assessing performance and repairs, designing and implementing improvements and disposing of redundant assets. This is a shift in common practice, with broad asset management principles playing a much larger role than previously narrow focused guides (SAM Theme, 2007)

The term "guide" is distinct from a "handbook" or a "manual" which is a more definitive document. A "guide" assists a technically competent practitioner with a broad, but not expert, knowledge of the field of application to arrive at the best approach for a particular asset or asset system. This would also use the phrase "decision support", not "decision making", for this. Further important uses are to enable someone with a technical background to understand the broad procedures that an experienced practitioner would carry out. A guide can also provide useful training material. "Good" practice is technically competent and well-informed, but not necessarily the "best". The latter might not be readily available or recorded.

The guide must take a risk, performance and systems based approach. Any asset will have a primary function of flood management, coast protection or drainage to which performance objectives or standards will apply. All assets will also have various secondary functions - e.g. environmental, amenity, Health \& Safety, access etc.- -which can impose significant performance requirements. The broad framework for addressing risk, performance and uncertainty is described in Defra/EA Technical Report FD2302/ TR1-Risk Performance and Uncertainty in Flood and Coastal Defence.
In drafting good practice guidance, the author must consider the various management interventions that will be needed to achieve the performance requirements of the asset over its whole life cycle. The planning and/or design of any intervention will involve one or more of the following:

a. THE ASSET STATE: understanding the state of the existing asset and how this changes with time. Knowledge of this may be drawn from several sources - e.g. held by local operational staff, archived as asset data, recorded generically in the literature, obtained by investigation.

b. THE ENVIRONMENTAL CONTEXT: understanding the environmental context and how this is changing / might change with time. This relates both to future loading and design conditions on the asset, and to how the asset impacts on the environment.

c. THE ASSET PERFORMANCE: assessing the performance under present and future design conditions. This could cover primary and secondary functions. Performance is assessed over a range of conditions, including extreme loading conditions (residual risk). Performance relates both to the asset as a whole, to its component elements, and to the system of which it's a part.

d. ASSET DESIGN: designing and specifying the intervention. This could be routine maintenance, repair, rehabilitation, adaptation or decommissioning works for an existing asset, or construction of a completely new asset. The outputs of this process will be (a) construction drawings and specification; (b) design records; and (c) operation and maintenance instructions, which include monitoring.

The guide will need to establish the context within which it is being written, for e.g. environmental targets, mapping or planning. It should also establish itself alongside other technical guides supporting flood and coastal erosion risk management asset management. When considering the format of the guidance, the end user will need to pay careful consideration to ownership. With frequently changing legislation and operational targets the owner of the resulting document may need to update the guidance regularly. It may be easier to facilitate this through web applications rather than a pdf. document.

\section{IDENTIFYING BARRIERS AND FACILITATORS}

There is no doubting that the delivery of science into practice requires considerable effort, and that the delivery requirements can often be underestimated in the initial planning (Section 3 above). By sharing the lessons learnt through the delivery 
of a Performance-based Asset Management System (PAMS) it is hoped that both the 'barriers' and 'facilitators' can be better understood and perhaps more easily negotiated in other scientific projects of a similar nature. A summary of many of the barriers and facilitators that are to be discussed are outlined in Figure 2.

\subsection{Dissemination and Implementation}

Dissemination, Communication, Uptake and Implementation are commonly used terms, but are often interpreted in very different ways. The FLOODsite Communication and Dissemination Plan goes some way to trying to interpret their requirements and to help facilitate processes at these different levels (www.floodsite.net $/ \mathrm{html} /$ dissemination.htm). Dissemination simply makes the scientific outputs available. Implementation enables the outputs to be 'taken up' into practice.

\subsection{Communication}

The need for on-going and extensive communication is often underestimated. Communication activities such as workshops and piloting were built into the initial detailed plan of the PAMS project and a continuously updated communication plan ensured that all parties were aware of expectations. However, even with an extensive plan in place the time required to keep informed of developments within the project and in touch with other initiatives running parallel to the project has been considerably greater than first estimated.

The suggested communication 'actions' outlined in Figure 3 can to some extent be seen as cumulative. Some of the key benefits are;

\begin{tabular}{|c|c|}
\hline BARRIERS & FACILITATORS \\
\hline Scepticism of the Science & \multirow{2}{*}{$\begin{array}{l}\text { Proof of concept through } \\
\text { demonstration }\end{array}$} \\
\hline \multirow{2}{*}{$\begin{array}{l}\text { Reluctance to change } \\
\text { practice }\end{array}$} & \\
\hline & $\begin{array}{l}\text { Customer engagement from outset } \\
\text { Gaining 'buy in' }\end{array}$ \\
\hline $\begin{array}{l}\text { Reluctance to determine } \\
\text { scientific needs }\end{array}$ & \multirow{2}{*}{$\begin{array}{l}\text { Understand the realisation of } \\
\text { benefits }\end{array}$} \\
\hline \multirow{2}{*}{ Non-committal users } & \\
\hline & \multirow{3}{*}{\begin{tabular}{|l} 
Clear expectations/role \\
$\begin{array}{l}\text { Good financial planning and } \\
\text { review }\end{array}$ \\
\end{tabular}} \\
\hline Budget & \\
\hline \multirow{2}{*}{$\begin{array}{l}\text { Science perceived as too } \\
\text { 'high risk' }\end{array}$} & \\
\hline & Risk management criteria set \\
\hline Inability to use product & \multirow{2}{*}{$\begin{array}{l}\text { Training/skill set should be } \\
\text { identified at outset }\end{array}$} \\
\hline \multirow{2}{*}{$\begin{array}{l}\text { Commercial advantage in } \\
\text { scientific development }\end{array}$} & \\
\hline & \multirow{2}{*}{$\begin{array}{l}\text { Clarity in prior rights (into and as a } \\
\text { result of the science) }\end{array}$} \\
\hline \multirow{2}{*}{$\begin{array}{l}\begin{array}{l}\text { Need for development } \\
\text { before Science completed }\end{array} \\
\end{array}$} & \\
\hline & Manage expectations \\
\hline $\begin{array}{l}\text { IT system architecture } \\
\text { complexity }\end{array}$ & $\begin{array}{l}\text { Early engagement with IT } \\
\text { programme within Science }\end{array}$ \\
\hline
\end{tabular}

Figure 2. Barriers \& Facilitators of turning Science into Practice.
- Sense of ownership by the end user

- Promotion and awareness raising

- Lessons learnt before development

- Real problems considered/tested

- Realistic expectations

- Resource availability (manpower)

The PAMS project found that a simple newsletter has been very effective in keeping people aware of developments. The success of the newsletter was only drawn to the teams attention when one wasn't provided for a period of time and many people enquired after its whereabouts. The lesson to be learnt here is that just because you don't receive any feedback doesn't necessarily mean its not appreciated.

1. Building realistic expectations

2. Clear framework of outcomes and awareness of gaps being filled

3. Uptake champions (with suitable support materials)

4. Provide information in appropriate media

5. Involvement in work (ownership)

6. Involvement in Pilot Sites

7. Lessons learned and before/after comparisons with regard to Pilot Site outcomes

8. Reality workshops solving real (user brought) problems.

Often a single science project forms a critical component of a far larger science matrix. The complexity of the PAMS project is discussed later in relation to Figure 4. When delivering a science project it is essential to understand the wider dependence on the research, not only to get a sense of purpose and motivation, but to understand the wider dependents on the project. The PAMS project has provided unplanned value in building good relationships between the parties involved. There are excellent working relationships in place between Royal Haskoning, HR Wallingford, Strathclyde University and Halcrow Ltd, who have developed considerably by allowing trust to form a large basis of the relationships.

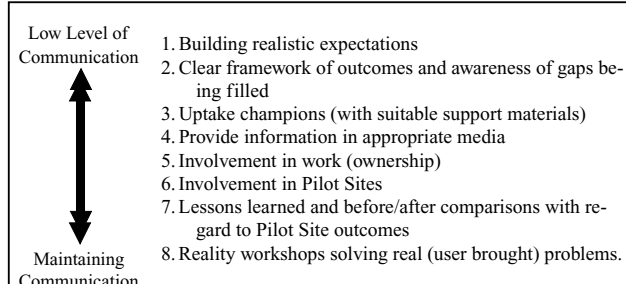
ing filled 3. Uptake champions (with suitable support materials) 4. Provide information in appropriate media 5. Involvement in work (ownership) 6. Involvement in Pilot Sites

7. Lessons learned and before/after comparisons with regard to Pilot Site outcomes gard to Pilot Site outcomes
8. Reality workshops solving real (user brought) problems. Maintaining

Figure 3. Communication channels (www.floodsite.net/ $\mathrm{html} /$ dissemination). 


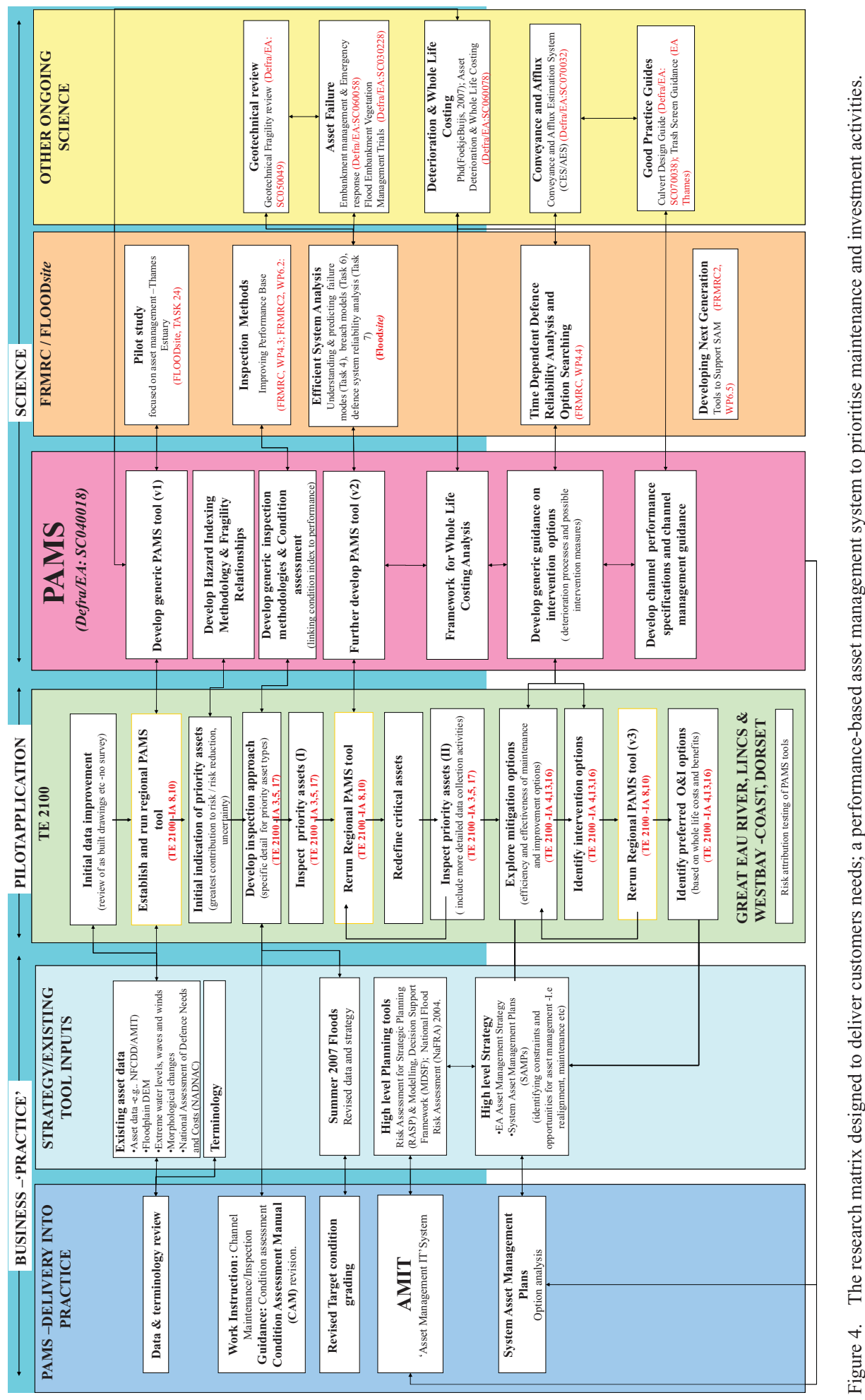




\subsection{Working together-Consortiums}

The time and effort spent in setting a consortium in place is often well rewarded as the transfer of knowledge tends to occur more readily between parties involved. This has certainly been the case within PAMS, where contractors, universities, government and industrial organisations have pulled together. The key to setting a successful consortia in place is to have a full and firm understanding of contractural requirements, signed up to by all parties. Consortia tend to work together best where each recognises the inputs of others and where the IPR is maintained by with the generating partner with others free to use it. The longer term benefit of this contractural arrangement can also be seen in terms of PII (section 5.6) through involvement of the potential consultant likely to be responsible for role out and implementation.

\subsection{Managing expectations}

There is inevitably a tendency for a customer of good research to want the scientific development before it has been completed. Experience with the CES/AES has shown this to be a very good state to be in, as it ensures full engagement of the end users who can support the refinement of the scientific outputs. It was through these discussions that the decision was made to hold back the release of the standalone version until the Afflux Estimation System (AES) component was completed.

Expectations both of the timescales and the final product should be managed very carefully. Components of science should be peer reviewed and delivered in completeness to a pre-determined time scale, so the pressure to use interim or draft outputs is removed. A failure to deliver on time often causes larger consequences than the independent science team perceives, due to the repercussions this has on connecting requirements. The science team must be aware of surrounding dependents, agreeing to stick to a realistic timescale for delivery.

In order to facilitate awareness of the project it is advisable to have a staged plan, which draws attention to key stages of the project (refer to section 3). This clarity also enables the operational staff to appreciate the manpower required to engage appropriately with the research. A lack of commitment in resource from the operational/user side is unfortunately common due to research competing with many 'day job' priorities. The effort spent in getting this right is often repaid through a reduction in resistance to change operationally as the science is delivered.

\subsection{Managing change effectively}

Responsive project management often results in changes to the original contract, as in the case with
PAMS where a number of 'measured steps forward' (MSFs) were initiated. Useful variations such as these are not always as simple to carry out in practice. Not because of the scientific challenges, but because of the administrative requirements of change control. The time it will take to receive the appropriate level of approval for the changes will differ dependent on the type of research project. To minimise the potential delay to changes within the PAMS project the approvers were briefed on the changes to be made before the 'change' paperwork was provided to them. Not all approvers were aware of the project detail and by preempting questions, a far more timely response was provided.

\subsection{IPR, SLA's and Contract Insurance}

F\&CERM research is a mature science activity and seeks to move forward collectively for altruistic reasons for managing our environment. This view however is counter to the commercial imperatives of organisations who wish to protect their own assets or interests. Within the context of a mature area of research it is rare to find an issue that hasn't already been researched or reviewed at some time previously.

The need to identify the owner of research innovation (outside of improved decision making) means that it is important to understand the Intellectual Property Rights (IPR) for both the inputs and outputs of the research and any terms on future use. UK Government guidelines on awarding research contracts are that ownership rests with the Public Sector Research Exploitation (PSRE) /contractor or Funding body best able to exploit the resulting IPR i.e. often the PSRE not necessarily the funder. If owners no longer freely share outputs, this may increase the cost of development or lead to problems in product accessibility, which would be detrimental to implementation and maintenance requirements, where access is crucial.

Service Level Agreement (SLA) discussions often happen when contracts are negotiated for the maintenance of the developed systems. They are a necessary requirement to ensure operational consistency. Without effective negotiation, projects can experience prohibitively high maintenance costs, especially initially when the systems likely performance is unknown. Some innovations have struggled to implement in the operational environment due to stringent operational requirements of the SLA's. This will need to be considered very carefully by the lead end user of the research as early as possible in the scientific development phase.

Suppliers and contractors use purchased insurances to protect themselves against potential contract liabilities e.g. breach of 3rd party intellectual property rights or failure to provide robust professional advice. If the supplier does not hold appropriate 
contract insurances at the point of tendering, they may offer to purchase additional insurance cover , the costs of which they are likely to pass on into their bid. Developing a robust understanding of the true project liabilities through a risk based approach, helps ensure that any additional proposed by suppliers costs are appropriate. The exact liability associated with a project is often difficult to derive due to differing interpretations of the risk involved. Sometimes liability levels derived are significantly higher than the contract fee e.g. 20 times the contract value. To minimise the time taken over agreeing insurance requirement it is important that funders clearly state their insurance requirements when advertising the science. The liabilities and insurance agreed at the out-set of the project should be kept under review as changes to project scope may affect the levels of security required.

Contract Insurance comes to the fore front when a new system requires to be implemented whose intended use is to underpin critical decisions and/or large investment decisions. A good example of this is the CES/AES, a tool which was funded by a large number of stakeholders (EA, Scottish Government and the Rivers Agency-Northern Ireland) and where the resulting rights were spread across these parties. The EA undertook the responsibility to ensure that liability connected with the system was well considered for all parties and multiple users before release. Even though the liability clause for this contract was outlined in the original contract it required legal scrutiny before the release of the product. The time taken to carry out this review was lengthened by the need for new staff to familiarise themselves with project history. The lesson to be learnt is to maintain engagement with legal and procurement staff throughout a project and be very clear on the potential liability associated with resulting products. Effective and ongoing liaison with procurement and legal teams will help manage funders risk in these areas. Issues in IPR, contract insurance and SLA's can potentially be foreseen at the start of a project and every effort should be made to ensure that they don't become insurmountable obstacles.

\subsection{IT systems}

IT systems and the complexity of the architecture underpinning systems should never be underestimated when developing research of an IT nature. Significant time was built into the PAMS contract to ensure that architectural requirements were fully scoped at an appropriate time (I.e., when the science is understood to feed into the system. PAMS will feed into the newly developing Asset Management IT (AMIT) system, which provided a clear process map in 2007. The PAMS team are currently providing potential architectural linkages to this system. Early engagement with the AMIT team has been essential resulting in the PAMS project milestones being reviewed in light of the AMIT team schedule.

\subsection{Data and terminology}

One of the 'measured steps' under the PAMS project is to provide clarity in terminology, in regards to such terms as asset criticality, residual life, standard of protection and standard of service. This has proven challenging due to different users having different perspectives, but essential so that users have a common understanding. The PAMS project also outlines data requirements, so that compatibility and demands on data capture can be assessed. One of the key databases which feeds PAMS is the National Flood and Coastal Defence Database (NFCDD). As this database is being subsumed into AMIT there is little risk of data not being available to underpin the PAMS methodology. The PAMS team has been working with the AMIT team closely in identifying the priority data requirements and where large benefits can be gained from improving uncertainty.

\subsection{Understanding parallel initiatives}

In order to prove the concepts being developed within the PAMS methodology it was essential to draw on major parallel projects including FLOODsite (EU Framework Programme 6), and the Flood Risk Management Research Consortium-FRMRC (EPSRC). Both consortiums are supported by Defra and the EA (Fig. 4). These larger projects, alongside the PAMS project helped the Thames Estuary to develop a risk based approach for asset management within the estuary. These connections have not only enabled the concepts to be proven, they have developed trusting relationships between institutions.

Parallel projects often funded by other parties, address discrete scientific issues that feed into supporting guidance and development of the system itself. There are three categories that the parallel research can be divided into-supporting research, additional research and coordination. An example of supporting research is the visual inspection improvements developed by Nottingham University under the EPSRC funded FRMRC programme. This research did not directly feed into the PAMS research project, but will improvements in the data collected and fed into the AMIT system for analysis. The Asset Deterioration and Whole Life Costing research project (SC060078) is a good example of 'additional' research. This was identified as a further requirement of the PAMS project, but was awarded separately to the project in order to focus on the specific issue. The final category-'coordinating' research overviews 
similar activities and provides a cross-check between developments. For example, a project commissioned by the EA and carried out by Strathclyde University reviews geotechnical fragility developments carried out in PAMS, FRMRC and FLOODsite (Defra/EA F\&CERM: SC050049).

\section{PROOF OF CONCEPT-PILOTING}

PAMS piloting of the concepts is to be carried out at the Great Eau (fluvial), Westbay, Dorset (coastal) and the Thames Estuary (heavily modified). These sites test requirements and are well interconnected with other activities in these areas. For example the Embankment Vegetation Management Trials (Defra/ EA F\&CERM: SC030028) allows an understanding of potential failure of embankments to be tested against the PAMS methodology. Piloting not only enables scientific principles to be tested, it enables potential end users to become more engaged with the developments. Improving the understanding of the potential that can be achieved they often become advocates for the research, helping to promote the uptake and change current practice. The importance of discussing the piloting sites with potential end users is often understated. The end users will know where the testing of the science is most beneficial.

\subsection{Thames Estuary-TE2100 project}

The Thames Estuary TE2100 project uses the SourcePathway-Receptor approach, refining RASP methods developed under the Defra/EA F\&CERM science programme (Sayers and Meadowcroft, 2005) and in particular a modification of the High Level Methodplus used for the National Flood Risk Assessment (Gouldby et al, 2007). It also incorporates advances proposed for the new Management and Decision Support Framework (MDSF2) (Surendran et al., 2008), such as improved flood spreading, developed under TE, EC and EA funding.

Phase 2 of the TE2 100 project was a data and information gathering phase. It pulled together a number of wider strands of research (e.g. FLOODsite Theme 4, FRMRC work package 4) to enhance flood risk planning within the estuary (Townsend et al., 2007)(Fig 4). The PAMS developed tools, piloted within TE2100, have been prototypes adapted specifically for the TE2100 tasks. Three key piloted areas of the PAMS project are described here:

\subsubsection{Condition assessment-The CAM}

Stage 2 of the IA8 Model TE2100 piloted the PAMS Phase 2 Condition assessment procedure which made use of new flow charts for assessing "performance features" from which the overall condition index was built up via agreed algorithms reflecting the emphasis on different failure modes. The large-scale data-gathering exercise to check the condition of the current defences represented a major step beyond current practice. The concept of visual performance indicators was developed under the FRMRC Infrastructure theme 4, (Long et al., 2006).

In parallel, the EA revised the Condition Assessment Manual (CAM) for flood defence assets (EA, 2006). This did not formally incorporate the performance features but did encapsulate much of the thinking. As a result it now includes better guidance on assessing the performance of a defence based on its visual condition.

\subsubsection{Reliability assessment of active structures}

PAMS models the reliability and deterioration of flood defences using 'fragility curves'. These are used to identify the defences and failure modes responsible for most of the risk attribution. TE2100 undertook a reliability assessment of the active (point) structures within the estuary system e.g. Thames Barrier, floodgates, flapped outfalls. A hierarchical approach to the reliability analysis was developed within the model where by assets which manage flood risk significantly could be prioritised. These assets then warranted closer investigation, whereas assets attributable to the lowest level of risk received lowest investigation (EA, 2006).

\subsubsection{Reliability assessment}

TE2100 phase 2 supported the application of reliability concepts, such as fragility and probabilistic analysis through the application of the IA model. The time dependant deterioration properties of flood defences were explored via a TE2100 PhD researcher at Newcastle University (Buijs, 2007). The refinement of the reliability concepts and resulting deterioration analysis fed straight back into PAMS.

\subsection{TE2100-Taking PAMS to the next level}

The IA8 risk model is currently going through further refinement-TE2100, Phase 3 (EA, 2006). Improvements to the model will investigate further the reliability concepts. "Thames Specific" fragility curves are being developed and used to make modifications to the range of defences (Simm et al., 2008).

\section{RECOMMENDATIONS}

No two projects are alike and each should be treated in its own right however, generic 'lessons learnt' outlined below are suggested to help maximise the success of uptake. These recommendations are not solely aimed at the scientist. Many of them require end-user input. 
1. Ensure timescales and reasons for key dates are clear within the project plan

2. Promote collaboration within and between projects, developing relationships and building trust between organisations

3. Manage expectations of the science, reducing the pressure to provide draft or interim reports before a thorough review has taken place.

4. Try to plan realistically for product review and project changes, both of which are often underestimated.

5. Allow time in the project for communication, both in development of the research and in keeping aware of wider changes which may effect the original plan.

6. Identify implementation routes at an early stage in the project lifecycle, so the purpose and format of the resulting products are clear.

7. Ensure the IPR expectations are clear from the outset (and reviewed throughout development) for both the products being used to develop research and the resulting product.

8. Demonstrate utility to industry where appropriate. Using pilots where possible.

9. Allow the scientific research to be adaptable (within reason) to reactive changes and requirements

10. Robustly question and prioritise the scientific developments prior to commencing the research. Ensuring it meets the key industrial/scientific needs.

11. Follow a good project management framework such as PRINCE (www.prince.com).

12. Promote the scientific advances to reduce scepticism and demonstrate the applicability

13. Maintain contact throughout a project lifecycle with legal, procurement and IT services especially where a new system is being developed.

The hard question that remains is whether there is enough resource, particularly manpower, to provide this level of engagement from an industrial perspective. Perhaps the focus should be on trying to consolidate and collaborate on projects of a similar nature. Fewer projects will allow more industrial input.

\section{ACKNOWLEDGEMENTS}

The views expressed in this paper are of the author and do not necessarily reflect those of the organisations mentioned. For Information on the Joint Defra/EA F\&CERM R\&D Programme and its outputs refer to www.defra.gov.uk/environ/fcd/research.

\section{REFERENCES}

Buijs., F. 2007. Time Dependant Reliability Analysis of Flood Defences. School of Civil Eng. and Geosciences. 2007.

DEFRA/ ENVIRONMENT AGENCY, 2008. http://www/ defra.gov.uk/environ/fcd/research/RandDProgCon/sam. htm [accessed 1/6/2008]

ENVIRONMENT AGENCY, 2006. Condition Assessment Manual (CAM)

ENVIRONMENT AGENCY. 2006b. TE2100 IA5: Reliability of Active Structures. WS Aktins.

ENVIRONMENT AGENCY. 2006c. Thames Estuary 2100 IA8 \& 10: Performance Bases Asset Management Version 3. HR Wallingford.

Gouldby BP, Sayers PB, Mulet-Marti J, Hassan M, Benwel D 2007 A method for regional scale flood risk assessment and its application to the Thames Estuary, Proceedings of the Institute of Civil Engineers

Long, G, Mawdesley, M, Simm, J (2006) Improved Approaches to Condition Assessment-Vol 1: Performance-Based Visual Inspection of Flood Defence Assets \& Vol 2: Detailed Technical Report, FRMRC.

Mcgahey C., Samuels, P., Knight, D., Hare, M. 2008. Estimating river flow capacity in practice. Journal of Flood Risk Management vol 1. Issue 1.

SAM THEME., 2008. Note on SAM good practice guides. Defra/Environment Agency Flood \& Coastal Erosion Risk Management R\&D Programme paper.

Sayers, PB AND Meadowcroft, IC. (2005) RASP - A hierarchy of risk-based methods and their application. Proceeding of the 40th Defra Conf. of River and Coastal Management

Simm, J., Gouldby., Sayers, P., Flikweert, J., Wersching, S. and Bramley M. 2008. Representing fragility of flood and coastal defences: getting into the detail. FLOODrisk08 conference paper

Surendran, S., Linford, T., Evan, E., Mcgahey, C., Sayer, P. \& Wickes, J. 2008-System based risk modeling and decision support for the UK catchment and coastal and estuary flood management planning. Defra/EA Flood Management conference.

Townsend, I., Elliot, C, and Sayers, P, 2007. Controlled dissemination and uptake of research. Defra Flood Management Conference-Paper 05a-1. 


\title{
Fluid thinking...smart solutions
}

HR Wallingford provides world-leading analysis, advice and support in engineering and environmental hydraulics, and in the management of water and the water environment. Created as the Hydraulics Research Station of the UK Government in 1947, the Company became a private entity in 1982, and has since operated as a independent, non profit distributing firm committed to building knowledge and solving problems, expertly and appropriately.

Today, HR Wallingford has a 50 year track record of achievement in applied research and consultancy, and a unique mix of know-how, assets and facilities, including state of the art physical modelling laboratories, a full range of computational modelling tools, and above all, expert staff with world-renowned skills and experience.

The Company has a pedigree of excellence and a tradition of innovation, which it sustains by re-investing profits from operations into programmes of strategic research and development designed to keep it - and its clients and partners - at the leading edge.

Headquartered in the UK, HR Wallingford reaches clients and partners globally through a network of offices, agents and alliances around the world.

\section{HR Wallingford}

Working with water

\author{
HR Wallingford Ltd \\ Howbery Park \\ Wallingford \\ 0xfordshire 0X10 8BA \\ UK
tel $\quad+44(0) 1491835381$
fax +44 (0)1491832233
email info@hrwallingford.co.uk

\section{www.hrwallingford.co.uk}

